\title{
MAJOR ACCIDENTS
}

\author{
Stephen Miles
}

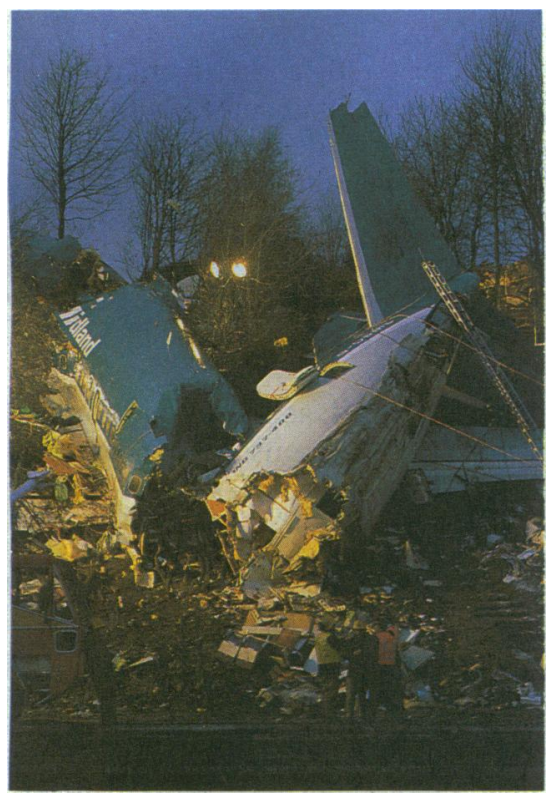

Major accidents affect individual hospitals rarely, but when they occur they cause total disruption of the hospital's normal activities. Large numbers of casualties arrive within a short space of time, and the presence of police and media representatives may complicate the proceedings considerably. To avoid chaos developing on such occasions the full implications of a major accident need to be considered, full major accident plans should be prepared, and adequate staff training must be undertaken.

\section{Types of major accident}

- Large fires

- Explosions-chemical - gas - gombs

- Public transport disasters-air -rail
-road
-sea

M1 aeroplane crash at Kegworth.

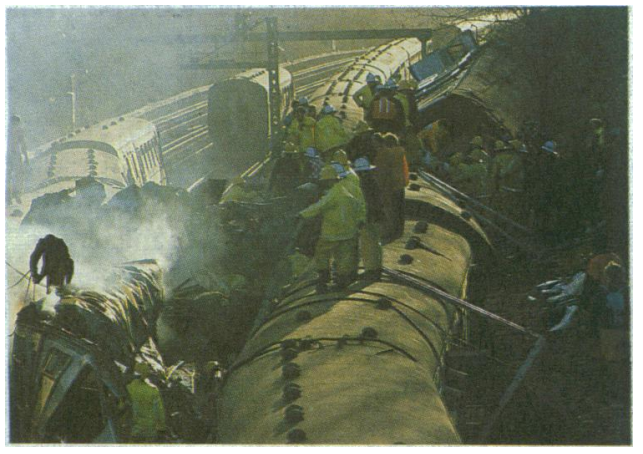

Clapham rail disaster.

\section{Factors in major accident planning}

- Staff resources

- medical

- nursing

- administrative

- Hospital resources

- space in accident and emergency department

- number of intensive care unit beds

- number of theatres

-equipment

- Special factors in area

-nuclear plants

- chemical plants

-inner city area (bombs, riots)

- motorways

- airports

- Availability of support from nearby hospitals
The actual number of patients the hospital is prepared to cope with should not be left to chance; a careful review of resources should establish how many patients in each category the hospital is able to deal with, and this figure should be communicated to the emergency services for incorporation into their own major accident plans. Each hospital will thus receive only a finite number of casualties, any additional patients being taken to other hospitals in the area.

When dealing with victims of a major accident most hospital staff are called on to perform in exactly the same way as they do at other times, albeit under considerable pressure. A small number of staff have specialised duties, which are described below. 


\section{Initiation of major accident procedure}

\section{Designated hospital}

- First informed

- Receives details of accident, estimated number of casualties, etc

- Provides site medical officer and (if required) mobile medical teams

- Receives first wave of casualties

\section{Supporting hospitals}

- Receive casualties when designated hospital is not able to cope

- If close to scene of accident may provide site medical officer and mobile teams so that designated hospital retains valuable staff

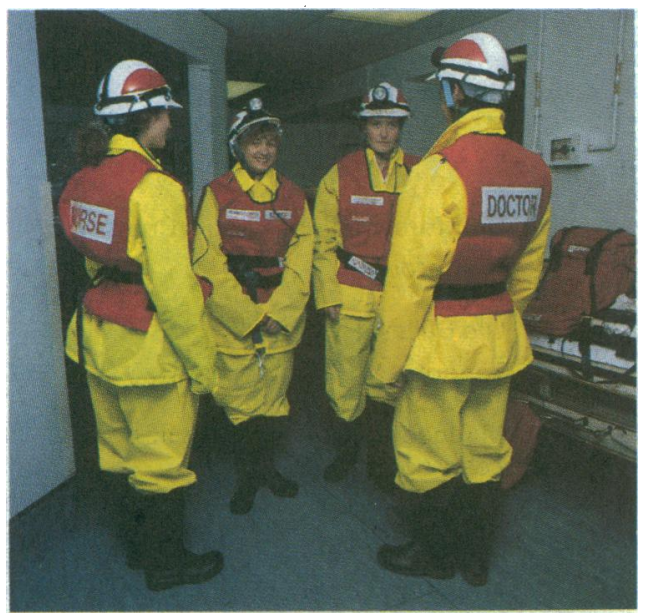

Emergency medical team in protective clothing.

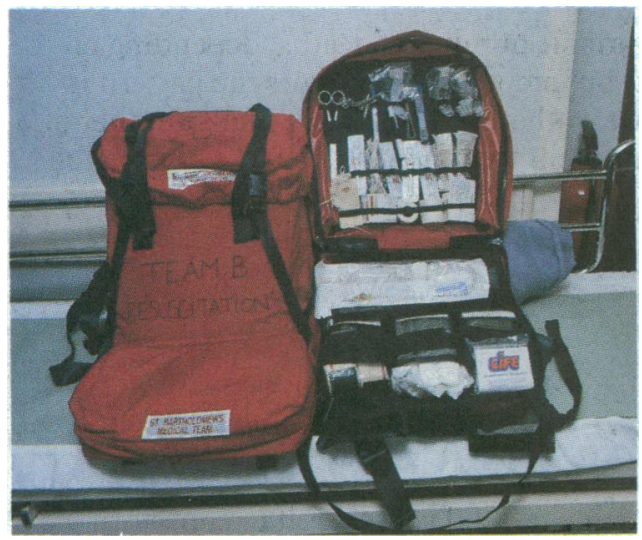

Equipment carried by medical team.

\section{Site organisation}

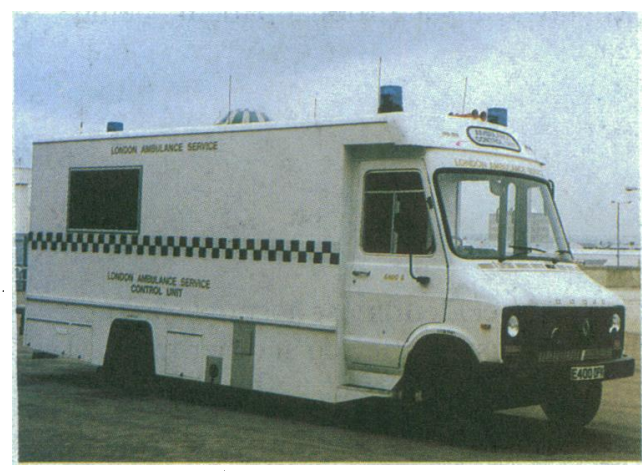

Emergency ambulance control vehicle.
As far as the hospital is concerned a major accident is any event that results in live casualties of a number and with injuries of a severity that call for extraordinary measures to be taken for their reception and treatment. The emergency services sometimes view things from their own perspective and may take refuge in a figure of 50 casualties as a trigger point for declaring a major accident. This is unhelpful to hospitals as 10 patients with serious injuries are far more difficult to cope with than 70 patients with minor injuries. Senior hospital staff may therefore sometimes have to take the decision to initiate the major accident procedure themselves.

Notification of major accidents, however, generally comes from the emergency services, usually the ambulance service, and comes to the hospital switchboard or the accident and emergency department. Information is given about the nature of the accident, the number of live casualties expected, and whether the hospital is a designated or supporting hospital. A designated hospital will receive the bulk of the casualties and will be the first to receive them. A supporting hospital will receive the overflow that the designated hospital is unable to deal with.

The notification of a major accident is often staged: as the declaration of a major accident causes considerable disruption and expense the emergency services understandably want to be sure that it is justified. Therefore such a declaration can be made only by a senior officer, and, while he or she is on the way to the scene, emergency vehicles that have already arrived report by radio to their headquarters.

When it is clear that something serious has occurred the designated hospital generally receives a major accident warning. Some hospitals do not take any specific action on receiving such a warning, but this is unwise. If the accident has occurred close to the hospital patients may begin to arrive within a few minutes, and a major accident may never be formally declared, either owing to confusion at the scene or because the senior officer present does not consider the declaration justified from his or her service's point of view.

For the reasons mentioned above when a major accident warning is received immediate preparatory action should begin. The medical, nursing, and administrative coordinators (described below) should assemble and establish a control centre. They should initiate the administrative measures required by the major accident procedure and summon the site medical officer and members of emergency medical teams to the control centre so that their presence may be noted. These personnel can then begin changing into protective clothing and assembling their equipment. It is appropriate to dispatch the site medical officer to the scene at this point.

The patients already in the accident and emergency department also have to be considered, and measures must be taken to empty the department. If the major accident warning turns out to have been a false alarm valuable practice in initiating the major accident procedure will have been gained by all participants; if the incident develops the hospital will be well on the way to being prepared for the reception of casualties.

On hearing of a major accident the emergency services always dispatch special emergency control vehicles to the scene. These are equipped with sophisticated communication systems and control the activities of members of their services who are working at the scene. The fire service is mainly concerned with evacuating casualties as well as controlling fire, smoke, and other hazards. The ambulance service is also concerned in evacuating casualties, administering first aid to them, and transporting them to hospital. The police are in charge overall at the scene and are responsible for sealing off the area, clearing roads to the hospital, keeping away unwanted sightseers, and identifying casualties. The three services each have a designated incident officer, and these liaise with each other. Hospital personnel arriving at the scene make contact with the ambulance control vehicle and the attending ambulance incident officer. 


\section{Duties of the site medical officer}

- Liaise with emergency services

- Assess the sciene

- Report to base hospital number of casualties and severity of injuries

- Inform emergency services if hospital unable to cope

- Check that mobile medical teams have the equipment they require

- Watch teams for signs of fatigue and arrange for replacements

- Notify hospital when the last casualty has left the scene

The site medical officer does not participate in treating patients

\section{Clothing for site medical officer and mobile medical teams}

- Safety helmet with headlight

- Bright reflective and waterproof clothing

- Tabards with designation clearly displayed ("doctor," "nurse")

- Wellington boots or other robust footwear

\section{Equipment to be carried to scene of accident}

Intravenous giving sets and cannulas

Plastic bottles of colloid solution

Sphygmomanometer, tourniquets

Intubation equipment

Stethoscopes

Suction equipment

Face masks and Guedel airways

Ambu bag

Chest drainage kit

Suturing kit with suture materials

Amputation kit

Drug box containing morphine, tranquillisers,

anaesthetic drugs (for amputation)

Syringes and needles

Inflatable splints

Scissors and pens

Bandages and dressings (various)

Adhesive strapping

Triage labels

\section{Site medical officer/medical incident officer}

The site medical officer is often, and with some logic, known as the medical incident officer and is generally the first doctor on the scene. He or she represents the hospital and liaises with the ambulance incident officer. It is important that the site medical officer does not attend to patients as this would compromise his or her other duties.

The question of who should fill the role of site medical officer is a vexed one. Traditionally it has been allocated to physicians, as they are not required at the hospital to treat casualties and, lacking surgical expertise, are less likely to concern themselves with treating patients at the scene. Unfortunately these doctors are likely to be completely at sea when confronted with the horrors of a major accident and may lack the authority to deal effectively with the emergency services.

The members of the British Association for Immediate Care (BASICS) specialise in rescue work and regularly participate in practice exercises. If there is a BASICS organisation close to the hospital it may be appropriate to enlist its services.

\section{Mobile medical teams}

The hospital may also be requested to provide mobile medical teams, normally consisting of a surgeon, an anaesthetist, and two to four nurses. They should be appropriately dressed and carry equipment in backpacks.

Heavy suitcases and boxes full of equipment are of little value in the awkward situations that may confront the teams at the scene of a major accident, and their transport to the scene from the nearest access point requires deployment of personnel that could better be used in evacuating and caring for casualties. The equipment to be carried is a matter of local choice, but the list in the box gives an idea of the range of items that should be carried. These should be divided appropriately among the various members of the team so that, for example, the anaesthetist has all the equipment required for care of the airway and the nurses have a reasonable supply of dressings. It is not usually necessary to carry oxygen in the packs as most ambulances have cylinders of it on board.

Apart from providing first aid and necessary treatment for patients with serious injuries the principal task of the site medical teams is to assess the patients as rapidly as possible and divide them into triage categories. This will enable the most severely injured patients to be transported to hospital first. This should be obvious; but, unfortunately, unless this procedure is carefully executed, the patients most likely to be transported first are the ones making the most noise, and these are frequently the least severely injured.

Once the patients have been allocated to triage categories, they should be labelled accordingly with clear reflective labels. Suitable labels are available from BASICS, and these have the advantage that the triage category of the patient may readily be altered if his or her condition warrants it. Such labelling at the scene of the accident not only helps in the orderly evacuation of the casualties but also makes for smoother reception of patients at the hospital.

Some patients may be trapped and may require drips, pain relief, etc, until they can be freed. Very occasionally it proves impossible, even with heavy cutting gear, to release a trapped person, and in these rare cases limb amputation may have to be considered. 


\section{Control centre equipment}

- Special stationery (prenumbered patients' notes, triage labels, etc)

- Staff control board (with list of roles and staff allocated to them)

- Patient control board (with names of victims, triage category, and disposal details)

- Spare telephones (for press room, police control point, etc)

- Signs (to direct relatives, press, etc)
The key to the successful running of a major accident procedure lies in establishing an effective control centre. This should be staffed by medical, nursing, and administrative coordinators, with appropriate support staff; all should be of the most senior rank possible (for example, an accident and emergency consultant, a senior nursing officer, a senior administrator) and be thoroughly familiar with the major accident procedure. They should liaise continuously to ensure that it is running smoothly.

\section{Medical coordinator}

Once the medical coordinator has established the control centre in conjunction with the two other coordinators his or her first priorities are to clear the accident and emergency department; to dispatch the site medical officer to the scene; and to organise the mobile medical teams, ensure that they are properly dressed and equipped, and arrange transport for them. Once this is done the chief task is to recruit and organise the medical staff. The medical coordinator has to check that the switchboard is calling in appropriate staff and summoning junior staff from residences and has to designate a relatively senior member of staff (usually a surgeon) to be triage officer. The triage officer receives the casualties at the ambulance entrance and allocates them to triage categories if this has not already been done at the scene; if it has been done he or she reassesses the patient's condition to ensure that the original designation is still correct and, having made this decision on triage, then allocates the patients to appropriate areas within the department.

The medical coordinator also has to organise medical staff as they arrive. This is an important task as staff commonly arrive in excessive numbers and may cause considerable confusion by acting independently without referring to the coordinator. At least two doctors are required for the resuscitation of any critically injured patients, and, if possible, one doctor should be allocated to each stretcher patient. A single doctor, supported by nurses, will be able to care for all of the patients with minor injuries until more medical staff become available.

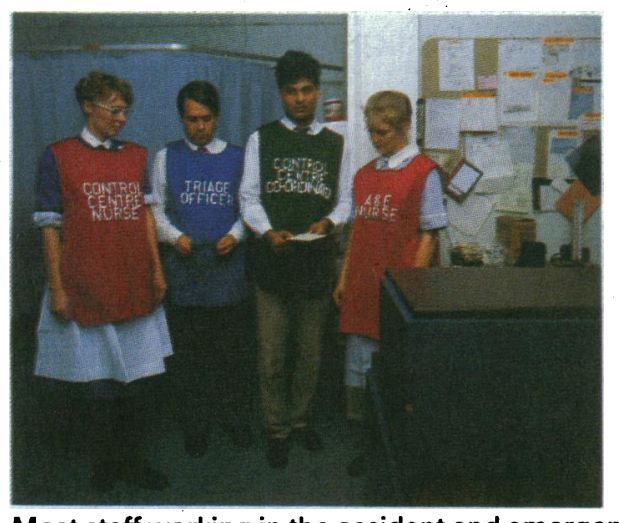

Most staff working in the accident and emergency department during a major accident procedure will not be fully familiar with its functioning. Officials and regular accident and emergency staff should be clearly identified so that they may help in locating. supplies of intravenous equipment, drugs, etc.
The medical coordinator also needs to establish, with the help of the nursing coordinator, which beds are available for those requiring admission and, in particular, what intensive care and theatre resources are required and how they may be provided. He or she should check that the doctors attending to the casualties are not becoming exhausted and ensure that they receive refreshments as required. Later on the medical coordinator may be required to address a press conference if requested by the hospital administration.

\section{Nursing coordinator}

The nursing coordinator's role is basically similar to that of the medical coordinator. He or she has to recruit nurses to go with the mobile medical teams and also to attend the patients in the accident and emergency department. Up to four nurses may be required for the resuscitation of a critically injured patient, and one nurse should be provided for each stretcher patient. In addition, the nursing coordinator should ensure that sufficient beds are cleared for the admission of patients with serious injuries and that patients who have been prematurely discharged to make way for the victims of the major accident are properly cared for. 


\section{Duties of the administrative coordinator}

- Ensure that clerical staff are stationed to collect basic information about patients as they arrive (on specially designed stationery)

- Organise security and portering staff to direct relatives, public, and press away from treatment area and organise erection of signs

- Organise police control point and press area and equip them with telephones

- Designate other administrative staff to act as press officer, patient information officer, police liaison officer, etc

- Check switchboard is coping with overload of calls and that call out of off duty staff is proceeding smoothly

- Ensure catering, pharmacy, and supply needs are met

\section{Administrative coordinator}

The administrative coordinator has perhaps the most complex role, and it is one that needs to be practised. The successful running of a major accident procedure requires a great deal of documentation and record keeping: firstly, to keep track of patients, particularly if they are to be discharged; secondly, to provide the police with the identification information that they require for running their casualty bureau; and, finally, to answer inquiries from relatives who arrive at the hospital. The administrative incident officer has to set up a room for the police to operate in so that they can collate their information and perform any necessary interviews. He or she has to organise a proper press area in a place suitably remote from the accident and emergency department, and arrange to brief the press at regular intervals. Porters and security staff have to be organised to ensure that patients are transported expeditiously and that unwanted people are kept out of the treatment area. An area for relatives has to be established, together with a quiet room for interviews with the bereaved.

As the incident proceeds the administrative coordinator has to keep checking that the switchboard is coping with the avalanche of incoming calls it tends to receive on such occasions and that the operators have been able to contact all the necessary personnel. He or she also has to attend to medical supplies and catering needs.

This infrastructure is highly complicated but is absolutely essential if the doctors and nurses are to be able to treat the victims of the accident expeditiously.

When information is received from an official at the site that the last casualty has been taken from the scene and when all patients have either been admitted or discharged the three coordinators decide on a stand down of the major accident procedure.

After the stand down staff need to be debriefed. At the least this entails recording details of events that have occurred during the major accident procedure while their memories are still fresh. Staff may also require counselling if they are overexcited or upset, and temporal needs such as meals and transport home must be considered.

\section{Major accident plan}

A hospital cannot possibly organise itself to receive the victims of a major accident without detailed planning beforehand. This planning is incorporated into what is usually a weighty document known as the Major Accident Plan. This contains details of all the actions that everyone associated with the incident will have to take, from consultants to catering staff. It is unrealistic to expect individual members of staff to be familiar with the entire plan, so their portions of the plan should be summarised in individual documents known as Action Cards. These should be distributed to all members of staff likely to have to use them in the event of a major accident. No plan is perfect, and all potential participants need to be tested by some form of practice. This also serves the valuable purpose of staff training. Such exercises may be simply to test communications, when the switchboard operators attempt to contact all the staff they would have to if a major accident occurred; or they may be more elaborate affairs that employ mock casualties - these are difficult to run and have a tendency to degenerate into farce; the emergency services occasionally organise large scale major accident exercises, and hospitals in the vicinity should seek to participate in these.

The photographs of the $\mathrm{Ml}$ and Clapham disasters were supplied by Frank Spooner Pictures and that of the emergency control vehicle by Mr C A J Keevil. Other photographs were taken by the education and medical illustration services department, St Bartholomew's Hospital.

Mr Stephen Miles, FRCS, is consultant in accident and emergency medicine, St Bartholomew's Hospital, London.

The ABC of Major Trauma has been edited by Mr David Skinner, FRCs; Mr Peter Driscoll, FRCS; and Mr Richard Earlam, FRCS. 